\title{
Percursos Jnterpretativos: a circulação midiática de enunciados destacados de Bolsonaro e a construção do discurso machista e autoritário
}

\author{
Ernani Cesar de FREITAS* \\ Maria Joana Chiodelli CHAISE**
}

\begin{abstract}
* Doutor (2006) em Letras pela Pontifícia Universidade Católica do Rio Grande do Sul (PUCRS). Pós-Doutorado (2011) em Linguística Aplicada e Estudos da Linguagem (PUC-SP/LAEL). Professor do PPGL/UPF e do curso de Letras. Contato: ecesar@upf.br.
\end{abstract}

** Doutoranda (ingresso em 2018) em Letras pela Universidade de Passo Fundo (UPF). Mestre (2010) em Ciências da Comunicação da Universidade do Vale do Rio dos Sinos (Unisinos). Professora do curso de Jornalismo da UPF. Contato: mariajoana@upf.br.

\begin{abstract}
Resumo:
Prática corriqueira atualmente na mídia, especialmente na rotina jornalística de edição de títulos ou outras chamadas, o destacamento de pequenos enunciados para circularem em outras arenas é uma forma de enfatizar e construir sentido. Este trabalho tem como objetivo descrever e analisar como se deu a repercussão de uma entrevista do deputado Jair Bolsonaro (PSL), candidato à presidência da república em 2018, a respeito de seu patrimônio e o recebimento do chamado 'auxílio-moradia', e qual o percurso interpretativo projetado pela mídia a partir da circulação dos enunciados destacados pelos veículos que reproduziram a entrevista original. Mobilizamos conceitos da análise de discurso francesa, em especial de destacabilidade, sobreasseveração e aforização propostos por Maingueneau (2008, 2011, 2014), para formatar um estudo exploratório, com cunho bibliográfico, mediante a análise de discurso. A análise empreendida autoriza a dizer que o destaque e a sobreasseveração potencializam a produção e a circulação de manobras enunciativas, orientando os leitores na construção de sentidos. Os leitores foram mobilizados a interpretar os destaques, procurando (re)construir ou (re)forçar o sentido de um candidato machista, autoritário e mesmo misógino, desacreditado para assumir um cargo no executivo nacional.
\end{abstract}

\section{Palavras-chave:}

Destacabilidade. Sobreasseveração. Aforização.

Signum: Estudos da Linguagem, Londrina, v. 22, n. 3, p. 10-28, dez: 2019 


\title{
Percursos Interpretativos: a circulação midiática de enunciados destacados de Bolsonaro e a construção do discurso machista e autoritário
}

\author{
Ernani Cesar de Freitas; Maria Joana Chiodelli Chaise
}

\section{INTRODUÇÃO}

Selecionar um acontecimento da vida cotidiana para alçá-lo a acontecimento midiático, em detrimento de tantos outros acontecimentos possíveis de serem publicados, pode ser considerada uma primeira operação do jornalismo em seu processo de construção da realidade (TRAQUINA, 1999). Contudo, após a seleção do conteúdo, outros mecanismos de construção de sentido são colocados em prática no momento de preparar o texto para ser apresentado à audiência. A criação e formatação de títulos ou linhas de apoio são formas de dar destaque ao conjunto do texto a ser publicado. Esses enunciados curtos, que resultam de uma lógica de extração de um fragmento de texto, são nominados, por Maingueneau (2008, 2011, 2014), como enunciados destacáveis, resultados de um movimento que opera uma produção de sentido a partir do recorte que é feito para ser publicado. Essas sobreasseverações, ou "pequenas frases", traduzem-se em textos descolados de seus contextos e cotextos originais e, pelo processo de deslocamento, tendem a sofrer alterações de sentido, deformação da pretensão original ou mesmo empobrecimento, dada a sua formatação em estilo de fórmula, como nomina Krieg-Planque (2010), além de circularem, eventualmente, fora do texto que fizeram parte na origem. Maingueneau (2008) considera que esses enunciados operam dessa forma por possuírem algumas características, entre as quais serem curtos, facilmente memorizáveis, estruturados de modo a impressionar e potencialmente reutilizáveis.

$\mathrm{Na}$ tentativa de compreender esse fenômeno, pretendemos discutir as manobras enunciativas na reprodução da entrevista publicada pela Folba de São Paulo do dia 11 de janeiro de 2018, com o deputado federal Jair Bolsonaro, candidato à presidência nas eleições de 2018. No texto, Bolsonaro é questionado sobre o uso do chamado auxílio-moradia, verba paga pela Câmara dos Deputados a quem não possui imóvel no Distrito Federal, e usada pelo deputado desde 1995, mesmo ele sendo proprietário de um apartamento em Brasília. Após a publicação inicial, instalou-se um acontecimento discursivo que iria, apesar de sua curta trajetória na mídia, render uma safra de matérias em diversos veículos da imprensa brasileira.

O objetivo, neste trabalho, é descrever e analisar como se deu a repercussão da entrevista e qual o percurso interpretativo projetado pela mídia a partir da circulação dos enunciados destacados pelos veículos que reproduziram a entrevista original. Pretendemos 
investigar o movimento de destextualização do contexto original da entrevista e os efeitos de representação que as manobras de sobreasseveração e aforização provocaram.

Este estudo exploratório, com cunho bibliográfico, mediante a análise de discurso, se inscreve na articulação das ciências da linguagem com as ciências da comunicação. $\mathrm{O}$ roteiro metodológico foi elaborado a partir da definição teórica e da escolha do corpus, constituído de seis enunciados de veículos online que repercutiram a entrevista. A análise desenvolveu-se a partir da mobilização das categorias teóricas (estruturas enunciativas) que embasaram os procedimentos metodológicos, tais como: sobreasseveração, destacabilidade, aforização e enquadramento.

\section{Da Construção de Realidade ao Destacamento}

É do aspecto discursivo que trata esse trabalho e, para tanto, consideramos essencial analisar as transformações pelas quais passa um texto até ser apresentado ao público, tendo em mente o entendimento de destacabilidade proposto por Maingueneau (2008). A noção diz respeito ao conjunto de propriedades que determinadas frases possuem, que as fazem circular, eventualmente, fora do texto de origem, em outros textos ou suportes, e as implicações que essa destextualização provoca.

Souza (2016) explica que uma série de enunciados pode receber esse estatuto, basta que, para isso, se apresentem como enunciados 'destacáveis', "Isto é, passíveis de serem destacados de um texto, graças à posição em que se encontram, ao sentido de definição ou generalização que lhe pode ser atribuído, à marca de uma operação metadiscursiva, à forma sintética e inusitada" (p. 468).

Maingueneau (2008) vai além nesse entendimento ao afirmar que o destacamento dos enunciados não se dá somente a partir das sequências destacadas, mas, sim, ao se considerar as condições que permitem que enunciados sejam destacáveis. A destacabilidade opera, então, uma possível 'destextualização' do texto, uma saída de partes do enunciado para uma operação de enfatização em relação ao todo textual. Esse realce pode resultar em manobras de eliminação de modulações, que reforçam a autonomia e o caráter lapidar do enunciado. Como resultado surge o que o autor nomina como sobreasseveração.

É desse movimento de sobreasseverar, também, que Krieg-Planque (2016) afirma serem criadas as 'pequenas frases', sendo a sobreasseveração o fenômeno pelo qual um fragmento se apresenta no discurso como destacável, por um caráter generalizante ou porque é objeto de valor estilístico, por exemplo. Na opinião da autora, a rotina jornalística tem tendência a favorecer a produção dessas 'pequenas frases', tanto por conta da periodicidade dos suportes e os imperativos rápidos, aos quais os jornalistas estão sujeitos, quanto pela natureza socioeconômica das atividades de produção.

Referente a esses quadros de produção de discursos, a 'pequena frase' é integrada à narração porque é construída como acontecimento, e ela é assim construída porque é associada a 
uma intenção, a uma posição, a uma doutrina, a uma ideologia, a um traço de personalidade, a uma opinião, a uma estratégia, a uma ambição, a interesses ou a um projeto, que a 'pequena frase' supostamente condensa ou dos quais ela supostamente é sintoma (KRIEG-PLANQUE, 2016, p. 25).

Ao discutir o movimento de circulação de enunciados - pequenas frases - e esse novo estatuto que a citação adquire, Baronas e Cox (2012) afirmam que, para além de uma 'máquina' de recortar e fazer circular enunciados, como propõe Maingueneau (2008), a mídia também deve ser considerada uma potente máquina de (trans)formar enunciados e produzir simulacros, segundo a(s) ideologia(s) de grupos, organizações e instituições que os veiculam. "Assim pensada, a mídia vai se patenteando muito mais como uma instância de circulação de sentidos e interpretações do que propriamente de circulação de fatos" (BARONAS; COX, 2012, p. 16).

Nesse contexto, podemos entender que os textos que circulam nas diversas mídias resultam de uma produção coletiva, na qual interagem diversos atores, os quais se apoiam em diversas lógicas de produção, que são potencializadas à medida que ocorre uma seleção de trechos que ganharão destaque. O mecanismo de recortar para destacar trechos, chamado sobreasseveração, é discutido a seguir.

\section{A Problemática que Emerge das Sobreasseverações}

Ao compreendermos que a sobreasseveração não é uma citação e, sim, um movimento de realce da enunciação, uma modulação da enunciação, que formata um fragmento de texto como destacável, precisamos elucidar como ela se dá na prática. A sobreasseveração é, por definição, de acordo com Maingueneau (2008), uma antecipação do destacamento. Portanto, a sobreasseração se aplica a todas as situações em que uma sequência breve se sobressai em um texto, como candidata ao que o autor nomina destextualização, ou seja, uma operação de realçamento do fragmento em relação ao cotexto.

Esse realce ocorre a partir de manobras diversas, como inclusão, modificação, exclusão e/ou apagamento de partes do enunciado. Ainda, o texto realçado pode estar próximo ao texto de origem, ou nem tanto. Daí a distinção ao que Maingueneau (2008) nomina de sobreasseveração forte ou fraca. No caso da forte, ele explica que são os enunciados dissociados do texto de origem na apresentação, a menos que os leitores façam uma busca para ter acesso à publicação original. Nesse caso, Maingueneau avalia que não é possível identificar se há fidelidade do texto relatado com o discurso de origem e é ampliado o processo de intervenção do locutor que cita. Essa sobreasseveração forte origina o destacamento forte e favorece, na opinião do autor, o processo de simulação e intervenção da máquina midiático-discursiva. "Do ponto de vista do funcionamento das mídias, para os leitores, esse texto de origem não existe” (p. 88). 
A segunda distinção é a dita sobreasseveração fraca, que promove o destacamento fraco. Nesse caso, o enunciado destacado está próximo do texto de origem, o que não significa que exista, necessariamente, concordância entre o texto relatado e o discurso de origem.

Esse é particularmente o caso de todos os fenômenos de colocação de título, em que o enunciado sobreasseverado se encontra, de alguma forma, integrado no corpo do artigo. Vimos que isso não implica uma grande fidelidade; bem ao contrário. Isso apenas confirma os resultados dos trabalhos recentes sobre o discurso direto, que acentuam seu caráter de simulação e a intervenção constante do locutor que cita (MAINGUENEAU, 2008, p. 88).

O autor também considera que não há como definir se a asseveração foi proposital do veículo ou do autor da enunciação. Mas enfatiza que as modificações acentuam o caráter de fórmula, favorecendo a sobreasseveração e, com isso, a destacabilidade.

Tornou-se, assim, uma rotina para os locutores que estão familiarizados com os procedimentos midiáticos situar enunciados em posições textuais escolhidas - muito frequentemente ao final da unidade textual -, de modo a torná-las destacáveis, a favorecer sua ulterior circulação. É como se os profissionais das mídias indicassem discretamente os fragmentos que desejam ver retomados (MAINGUENEAU, 2008, p. 83).

A sobreasseveração caracteriza, então, um enunciado relativamente breve e de estrutura pregnante, que está em posição relevante no texto ou em uma passagem do texto (condensado semântico), cuja temática deve estar em relação com o intuito do gênero do discurso; e que implica um tipo de amplificação da figura do enunciador. Tem-se, então, uma questão fundamental. Em qualquer um dos casos da sobreasseveração o movimento de destacabilidade implica um tipo de amplificação da figura do enunciador, "que não apenas diz, mas mostra que diz o que diz, e presume-se que o que ele diz condensa uma mensagem forte, induzindo a uma tomada de posição exemplar" (MAINGUENEAU, 2008, p. 82).

Esse movimento promove um efeito de discordância com relação à responsabilidade do enunciado. Se, por um lado, a sobreasseveração de certa forma desresponsabiliza o jornalista, a responsabilidade dos enunciados recai sobre a figura do sobreasseverador, que é alguém que se sobrepõe, que mostra um ethos ${ }^{1}$ de enunciador

\footnotetext{
${ }^{1}$ É necessário apresentar o conceito de ethos. Na avaliação de Charaudeau (2017), o conceito relacionase com a construção de uma imagem de si, de uma identidade, de uma corporalidade do enunciador por intermédio de um tom lançado por ele no âmbito discursivo. $\mathrm{O}$ ethos pode então ser percebido como o elemento que estrutura a relação de comunicação entre o enunciador e o seu destinatário, uma vez que "é bem o resultado de uma encenação sociolinguageira que depende dos julgamentos cruzados que os indivíduos de um grupo social fazem uns dos outros ao agirem e falarem” (p. 118).
} 
autorizado a enunciar. "Produz-se, assim, um desacordo essencial entre o locutor efetivo e esse mesmo locutor considerado como sobreasseverador de um enunciado que foi destacado pela máquina midiática" (MAINGUENEAU, 2008, p. 84). A discussão, então, se encaminha para um entendimento de que a sobreasseveração não pode ser remetida a uma única intenção. Maingueneau considera que os textos são um produto coletivo constituído de fragmentos textuais em mosaico, em que intervêm o locutor citado, seu agente, o jornalista, o paginador e o responsável pelo título.

Evidentemente, é o gênero que filtra o tipo de enunciados destacáveis semanticamente mais pertinentes. É normal que, numa entrevista, sejam de preferência as afirmações da pessoa entrevistada sobre si mesma as marcadas como destacáveis. Por outro lado, numa exposição filosófica, a destacabilidade diz respeito, acima de tudo, a teses, a enunciados genéricos de grande teor doutrinal (MAINGUENEAU, 2008, p. 84).

Todos esses processos relacionam-se, amplamente, à problemática que Maingueneau denomina autonomização da sobreasseveração. De acordo com ele, é bastante comum que a autonomização da sobreasseveração frente ao texto de origem promova "uma transformação do enunciado, ou de um ou de outro de seus parâmetros enunciativos, quando ele passa ao paratexto" (MAINGUENEAU, 2008, p. 88). Essas frases autonomizadas possuem propriedades específicas e são postas a circular de modo que, eventualmente, são interpretadas como se não tivessem feito parte de seus textos originais. São elas que, na opinião do autor, adquirem o estatuto de aforizações.

Parece-nos preferível não confundir uma lógica de sobreasseveração - que faz aparecer uma sequência sobre um fundo textual - e uma lógica de aforização (para ser exato, um destaque aforizante) que implica um tipo de enunciação totalmente diferente: outra figura do enunciador e do co-enunciador, do estatuto pragmático do enunciado. A aforização atribui um novo estatuto à citação (MAINGUENEAU, 2008, p. 92).

A noção de aforização aparece mais esclarecida quando Maingueneau (2014) agrupa, em um plano enunciativo, as "aforizações primárias", como provérbios, adágios, slogans, máximas, que são desprovidas de um texto fonte, e as "aforizações secundárias", resultantes de destacamentos de um texto fonte para compor outros textos, rotina permanente nas mídias ao evocar acontecimentos sociais. Em muitos casos, de acordo com o autor, o uso das aspas é o que diferencia os dois estatutos, e que configura o status de aforizador. Esse aforizador carece, na mídia, de um nome próprio, de uma identidade, na avaliação do autor. Uma hipótese, para ele, é a representação do aforizador por uma foto de rosto, o que funciona como uma assinatura e favorece seu reconhecimento como subjectum, uma confluência entre o sujeito jurídico/moral e o sujeito da enunciação que configura o aforizador. Contudo, o autor deixa claro que a apropriação do rosto não exclui a possibilidade de aforizadores coletivos. 
Indo mais a fundo no entendimento da aforização, cabe citar o conceito de regime enunciativo. Para Maingueneau (2011), a enunciação 'textualizante' inscreve cada enunciado no horizonte global de um texto proveniente de um gênero de discurso, seja ele monologal ou dialogal. Em contrapartida, a enunciação aforizante não entra na lógica do gênero de discurso, quer se trate de frases que são destacadas de um texto "por natureza', como o caso dos slogans, ou de frases que tenham sido destacadas de textos diversos. Porém, o autor compreende que não há enunciado que esteja fora de um gênero de discurso.

Maingueneau (2011) explica que numa enunciação aforizante, o enunciador fala a uma espécie de auditório universal, pois a aforização institui uma cena de fala em que não há interação entre os protagonistas. $\mathrm{O}$ aforizador mantém uma relação naturalmente assimétrica com um destinatário que não é um alocutário comum, mas um "auditório, uma comunidade imaginária consolidada por valores. No entanto, ele deve, na verdade, ser interpretado por leitores ou ouvintes, cuja atividade interpretativa é fortemente solicitada, já que a aforização não tem por natureza outro contexto senão aquele do texto em que se apresenta" (p. 19).

E o problema surge, na avaliação do autor, de acordo com os tipos de aforização que estão em questão. Maingueneau (2011) avalia que, no caso das aforizações destacadas de um texto, a interpretação está condicionada ao que ele chama de enquadramento, que ele compreende como categorias pragmáticas:

A mesma aforização será tratada diferentemente conforme o enquadramento ao qual a submetermos. Além disso, pode acontecer de haver um enquadramento que, nesse caso, seja apenas dominante. O problema que se apresenta, todavia, é saber o que orienta o destinatário para este ou aquele enquadramento. Existem índices de diversas ordens que interagem nessa questão. Alguns provém do gênero e do tipo de discurso: o jornalismo sério privilegia a dimensão informativa, a cobertura de celebridades atribui um amplo papel à expressão dos afetos, o discurso religioso ou a literatura favorecem a pesquisa de significações ocultas etc. Outros índices são mais estritamente linguísticos: salvo em casos excepcionais, uma aforização fortemente carregada de tropos ou enunciada em latim não terá um objetivo informativo. A identidade do aforizador desempenha um papel importante: conforme a aforização é atribuída a um sábio, um cantor, um filósofo etc., ela será relacionada a um tipo de enquadramento (MAINGUENEAU, 2011, p. 20).

Nesse aspecto, cabe destacar o entendimento do autor a respeito do enquadramento informativo e do enquadramento testemunhal. $\mathrm{O}$ primeiro tem por objetivo fazer saber, e é interpretável se o destinatário destaca a aforização sobre o fundo de um repertório de conhecimentos que são supostamente partilhados num determinado momento. $\mathrm{O}$ enquadramento testemunhal também tende a reduzir, ou mesmo anular a dimensão informativa em proveito da expressão de uma convicção diante do mundo. Ele assume modalidades bem diversas na avaliação de Maingueneau (2011): pode passar tanto por um apagamento enunciativo classificado como sentencioso, quanto por um superinvestimento subjetivo personalizante. 
É nesse contexto de alteração dos enunciados iniciais que se inscreve este trabalho, que tem a intenção de compreender o movimento de alteração dos enunciados quando são destacados, sobreasseverados. E que compreende a lógica de saída do texto para um movimento de destextualização como algo importante do ponto de vista da apresentação de percursos interpretativos e de produção de sentidos. Essa descontextualização é acompanhada por movimentos que exigem um trabalho interpretativo no jogo das estratégias enunciativas, o que será mostrado na sequência com a apresentação do corpus que será analisado.

\section{Sobre a Metodologia e a Seleção de Enunciados para o Corpus}

Este trabalho constitui-se num estudo de natureza exploratória, com cunho bibliográfico, mediante a análise de discurso. A linha condutora teórico-metodológica deste estudo se relaciona com as reflexões de Maingueneau (2008, 2011, 2014), essencialmente as que se inscrevem nas pesquisas que objetivam compreender o funcionamento dos processos de sobreasseveração, destacabilidade e aforização. Para efetivar essa análise, elegemos uma entrevista que o deputado federal Jair Bolsonaro, candidato à Presidência da República em 2018, concedeu à Folba de S. Paulo (MATTOSO; NOGUEIRA; BRAGON, 2018). O texto faz parte de uma série de reportagens publicada no período tratando de questões relativas ao patrimônio do deputado e de seus filhos, ${ }^{2}$ da suspeita sobre uma funcionária lotada em seu gabinete não trabalhar efetivamente, e do uso do chamado auxílio-moradia, verba destinada a políticos que não possuem imóveis no Distrito Federal, para reembolso de estada ou moradia na capital. ${ }^{3}$ Dois repórteres da Folba de S. Paulo viajaram à Angra dos Reis (RJ) no intuito de entrevistar Bolsonaro, que passava férias na casa que possui num condomínio do município. Camila Mattoso e Italo Nogueira conseguiram falar com o deputado, numa entrevista que não foi agendada. $\mathrm{Na}$ edição do texto a ser publicado, assina a matéria também o repórter Ranier Bragon, que cobre a Editoria de Política em Brasília. A entrevista foi publicada na íntegra, inclusive com frases duplicadas, típicas da linguagem oral. Essa opção se deu, aparentemente, por críticas anteriores do deputado ao jornal, com relação à manipulação de conteúdo que o jornal teria operado em publicações anteriores de entrevistas dele.

Para além da entrevista em si, a opção de análise neste texto também foi de compreender os sentidos emergentes da circulação da entrevista em outros veículos. Assim, para a formação do corpus, operou-se um movimento de seleção por meio de uma busca no site Google dos termos "Bolsonaro entrevista Folha". Na aba Notícias,

\footnotetext{
${ }^{2}$ BRAGON, R.; MATTOSO, C.; NOGUEIRA, I. Patrimônio de Jair Bolsonaro e filhos se multiplica na política. Folha de S. Paulo, 07 jan. 2008. Disponível para assinantes em: https://bit.ly/359w10g.

3 As reportagens foram publicadas após uma pesquisa do Datafolha apontar o parlamentar como o segundo colocado nas intenções de votos em todos os cenários. Os textos que descreveram a pesquisa foram publicados em dezembro de 2017. Não apenas Bolsonaro foi alvo das reportagens, mas todos os candidatos citados na pesquisa.
} 
uma grande variedade de resultados pode ser verificada. Por isso, alguns critérios de seleção foram estabelecidos para o corpus. O primeiro diz respeito à data da publicação. A entrevista ora estudada foi postada no site da Folha às 21h59min do dia 11 de janeiro de 2018. Dessa forma, o primeiro recorte foi selecionar apenas os registros datados do dia posterior à publicação, ou seja, 12 de janeiro, respeitando a instantaneidade característica do jornalismo. Em seguida, foram selecionados apenas conteúdos publicados por veículos de comunicação. Um terceiro elemento que funcionou como recorte foi a liberação de acesso de conteúdo, sendo que apenas conteúdos que podem ser acessados por não assinantes, ou que possuem versão gratuita temporária, foram selecionados. Em seguida, selecionamos para a amostra os textos que, de alguma forma, fizeram referência à entrevista base da análise e, por fim, separamos os textos que podem ser considerados destacados, a partir dos conceitos expostos neste trabalho. Dessa forma, o corpus foi formado por cinco enunciados, apresentados no Quadro 1:

Quadro 1 - Apresentação do corpus

\begin{tabular}{|l|l|l|}
\hline $\begin{array}{c}\text { Veículo onde o texto } \\
\text { foi publicado }\end{array}$ & Postagem & \multicolumn{1}{c|}{ Título (T) e linha de apoio (se houver) (LA) } \\
\hline $\begin{array}{l}\text { Folha de São Paulo } \\
\text { (Mattoso; Nogueira; } \\
\text { Bragon) }\end{array}$ & $11 / 01$ às $21 \mathrm{~h} 59$ & $\begin{array}{l}\text { T: "Tem que pegar o meu patrimônio. Esquece meus } \\
\text { filhos, diz Bolsonaro" }\end{array}$ \\
\hline $\begin{array}{l}\text { Gazeta do Povo } \\
\text { (Folhapress) }\end{array}$ & $12 / 01$ às $8 \mathrm{~h} 26$ & $\begin{array}{l}\text { T: "Dinheiro de auxílio-moradia eu usava para comer } \\
\text { gente", diz Bolsonaro } \\
\text { LA: À Folha de S. Paulo, deputado federal fala sobre } \\
\text { suspeitas levantadas a respeito da sua evolução } \\
\text { patrimonial, uso do auxílio-moradia e da contratação } \\
\text { de funcionários pelo seu gabinete na Câmara }\end{array}$ \\
\hline $\begin{array}{l}\text { Estado de Minas } \\
\text { (Cipriani) }\end{array}$ & $12 / 01$ às $9 \mathrm{~h} 03$ & $\begin{array}{l}\text { T: Bolsonaro diz que usou auxílio-moradia para } \\
\text { 'comer gente' } \\
\text { LA: Em entrevista em Angra dos Reis, o pré- } \\
\text { candidato à presidência afirmou ainda que vai vender } \\
\text { o apartamento de Brasília e morar em uma mansão }\end{array}$ \\
\hline $\begin{array}{l}\text { Revista Fórum } \\
\text { (Bittencourt) }\end{array}$ & $12 / 01$ às $13 \mathrm{~h} 18$ & $\begin{array}{l}\text { T: Bolsonaro para repórter da Folha: "Esse dinheiro } \\
\text { de auxílio moradia eu usava pra comer gente" } \\
\text { LA: O presidenciável perdeu a cabeça ao falar sobre } \\
\text { o uso indevido do auxílio-moradia }\end{array}$ \\
\hline $\begin{array}{l}\text { Diário Catarinense } \\
\text { Fong às } 14 \mathrm{~h} 40\end{array}$ & $\begin{array}{l}\text { "Como estava solteiro, esse dinheiro de auxílio- } \\
\text { moradia usava pra comer gente.", diz Bolsonaro }\end{array}$ \\
\hline
\end{tabular}

Fonte: Elaborado pela autora.

\footnotetext{
${ }^{4}$ Outras duas publicações se encaixaram nos critérios de seleção, porém elas são cópias de conteúdos já analisados: o Correio Brasiliense usou o mesmo conteúdo que Estado de Minas e o site Gaúcha ZH replicou o conteúdo do Diário Catarinense, o que os deixou de fora do recorte para a análise.
} 
Com relação aos procedimentos de análise, este estudo exploratório tem cunho bibliográfico, mediante a análise de discurso. A análise que segue desenvolveu-se a partir da mobilização das categorias teóricas (estruturas enunciativas) que embasaram os procedimentos metodológicos, tais como: sobreasseveração, destacabilidade, aforização e enquadramento (MAINGUENEAU, 2008, 2011, 2014).

\section{Os Efeitos da Sobreasseveração no Discurso de Bolsonaro}

Para compreender a lógica de circulação de notícias a partir da entrevista de Bolsonaro à Folha de S. Paulo, publicada em 11 de janeiro de 2018, é necessário retomar as condições de produção em que o diálogo entre os jornalistas e o parlamentar se deu. Bolsonaro encontrou os repórteres do jornal em frente à sua residência em Angra dos Reis, quando, então, o parlamentar foi inquirido. No total, foram 95 questionamentos ou afirmações que deram margem à exposição de opinião do pré-candidato à presidência. A opção da Folha ao apresentar o texto centrou-se em destacar o patrimônio do deputado, conforme demonstra o trecho a seguir, publicado na abertura da entrevista: "A Folha publicou no domingo (7) que o presidenciável e seus três filhos parlamentares multiplicaram o patrimônio na política, reunindo atualmente 13 imóveis em áreas valorizadas do Rio e Brasilia, com preço de mercado de cerca de R $\$ 15$ milhões" (MATTOSO; NOGUEIRA; BRAGON, 2018).

Ao compreendermos que a sobreasseveração não é uma citação, e sim um movimento de realce da enunciação, uma modulação da enunciação, que formata um fragmento de texto como destacável (MAINGUENEAU, 2008), podemos considerar que o título eleito pela Folha - "Tem que pegar o meu patrimônio. Esquece meus filhos", diz Bolsonaro -, não é uma opção de divulgação do acontecimento, apenas. Pode-se considerar que o enunciado encaixa-se na condição de título com sobreasseveração fraca, mas com alteração da frase a partir da inclusão do termo patrimônio. O enunciado também consagra o ideal de generalização, ao qual Maingueneau (2008) e Souza (2016) relacionam as sobreasseverações. Poderíamos propor uma fuga do parlamentar à sua prestação de contas com manobras de transferência de bens a familiares como um sentido latente que o jornal procurou promover, aliando-o ao grupo de políticos que têm essa prática como corriqueira. A carga semântica do vocábulo 'esquece', aliada à divulgação de uma notícia que trata de obscurantismo ligado ao enriquecimento de um político, tem todo um sentido latente, em especial ao tratarmos do atual momento brasileiro, em que os escândalos de corrupção se acumulam. "Esquece meus filhos" também poderia ser considerada uma tentativa de trazer à tona questionamentos a respeito do enriquecimento dos filhos de Bolsonaro, também parlamentares, que não são o foco da reportagem, mas são tratados tangencialmente.

O percurso interpretativo que a frase sobreasseverada manifesta ao leitor também é passível de recuperação de uma imagem autoritária por parte do deputado. O trecho 
destacado pelo jornal, em tom imperativo, constrói um sentido de ordem que o parlamentar poderia estar dando aos repórteres, o que reforça um estereótipo já bastante difundido na imprensa relacionado a Bolsonaro, que é militar da reserva.

Maingueneau considera normal que, numa entrevista, sejam as afirmações da pessoa entrevistada sobre si mesma as consideradas como destacáveis. Mas, ao ponderar que o texto é produzido a partir de enquadramentos (2008), fornece uma pista para análise da entrevista em questão. Quando a Folha de S. Paulo opta por um título que remete a uma manobra enunciativa com vistas a relacionar o nome de Bolsonaro, suas afirmações, destacadas entre aspas, e sua dificuldade em apresentar elementos concretos que justifiquem sua evolução patrimonial, pode-se recorrer ao chamado enquadramento testemunhal citado por Maingueneau (2011), já que fica evidente uma tentativa de redução, ou mesmo anulação da dimensão informativa em detrimento de uma convicção diante do mundo. Essa relação tem como índice também um trecho da entrevista ${ }^{5}$ que trata de uma declaração do candidato sobre sonegação de impostos, em que ele, além de assumir que sonegaria, também incita a população a sonegar, quando possível. Quando perguntado sobre a questão, o deputado diz: "Eu nunca soneguei. Eu sonego... 'Eu mato tudo quanto é bandido que vier pela frente'. Matei algum bandido?”, dizendo em seguida que a declaração tratava-se de um desabafo (MATTOSO; NOGUEIRA; BRAGON, 2018).

A entrevista em questão se investiu de distintos sentidos quando publicada por outros veículos de comunicação. O mais difundido, no recorte efetuado para análise, relacionava-se a uma afirmação de Bolsonaro sobre o uso que fez do dinheiro do auxílio-moradia. Os quatro textos que circularam no dia seguinte abordando o tema promoveram sobreasseverações que favorecem um percurso interpretativo que relaciona a imagem de Bolsonaro a um homem machista, hostil e até mesmo com características de misoginia, dadas as expressões chulas com as quais respondeu a repórter.

Para compreender esse percurso interpretativo, recorremos, primeiro, ao fragmento do texto inicial, na Folha de S. Paulo, o qual motivou as sobreasseverações dos demais textos, que serão analisados na sequência. $O$ fragmento que abre a publicação da Folha é: "Em entrevista à Folha nesta quinta (11), o deputado Jair Bolsonaro (PSC-RJ) voltou a criticar o jornal e a defender o recebimento de auxilio-moradia da Câmara, mesmo tendo imóvel próprio em Brasilia. Ele disse que pretende vendê-lo e pedir apartamento funcional. Questionado se usou o dinheiro do benefício para comprar seu apartamento, ele respondeu: 'Como eu estava solteiro naquela época, esse dinheiro de auxílio-moradia eu usava pra comer gente' (MATTOSO; NOGUEIRA; BRAGON, 2018).

Inicialmente é necessário dizer que, mesmo que promovam o que se pode nominar de aforizações secundárias (MAINGUENEAU, 2014), do ponto de vista de chamarem

\footnotetext{
${ }^{5} \mathrm{Na}$ entrevista à Folha, Bolsonaro diz ter cometido um "deslize" quando, em 1999, afirmou que sonegava impostos, e fez recomendação à população para que sonegasse "o possível" (COLON, 2018).
} 
nos títulos frases que podem ser lidas nos textos internos, marcadas inclusive com aspas, nenhum veículo que comentou a entrevista no dia seguinte a publicou na íntegra, o que, em termos de análise, promove o que Maingueneau chama de destextualização e realce do fragmento em relação ao texto original (2008). Os quatro textos que reproduziram a entrevista o fizeram a partir de uma manobra intencional, elegendo do todo uma parte para promover circulação de sentidos e distanciando os seus leitores do conteúdo completo da conversa entre o parlamentar e os repórteres da Folha.

Para repercutir a entrevista original, a Gazeta do Povo sobreasseverou: "Dinheiro de auxílio-moradia eu usava para comer gente", diz Bolsonaro. Na linha de apoio, o jornal seguiu uma linha mais informativa no seu enquadramento (MAINGUENEAU, 2011): “À Folha de S. Paulo, deputado federal fala sobre suspeitas levantadas a respeito da sua evolução patrimonial, uso do auxílio-moradia e da contratação de funcionários pelo seu gabinete na Câmara". A opção aqui fica mais clara do ponto de vista de ser um texto que procura descrever do que tratou a entrevista do parlamentar publicada pela Folha. Explorando o destaque do enunciado realizado pelo veículo, cabe apresentar o excerto que o jornal publicou como texto interno, de onde o título foi extraído: "Em entrevista à Folha de S. Paulo, o deputado Jair Bolsonaro (PSC-RJ) voltou a criticar o jornal e a defender o recebimento de auxilio-moradia da Câmara, mesmo tendo imóvel próprio em Brasília. Ele disse que pretende vendê-lo e pedir apartamento funcional. Questionado se usou o dinheiro do benefício para comprar seu apartamento, ele respondeu: "Como eu estava solteiro naquela época, esse dinheiro de auxílio-moradia eu usava pra comer gente” (GAZETA DO POVO, 2018).

Um primeiro indicador aponta que se trata de uma sobreasseveração fraca, justamente porque no interior do texto há elementos que apresentam o trecho eleito como destaque no título. Entretanto, há uma importante supressão. Se compararmos os enunciados dos títulos ao enunciado original, poderemos perceber a retirada da continuidade da frase dita por Bolsonaro: "tá satisfeita agora ou não? Você tá satisfeita?". Essa supressão é bastante importante quando se trata de produção de sentidos. A opção por opacificar esse trecho também cumpre um papel de tornar o título crível, ao mesmo tempo em que extrai elementos que parecem mais próprios da linguagem oral que de um texto jornalístico. Ainda, o tom de deboche e de contrariedade imbuído no texto extraído poderia reforçar o caráter de preconceito de gênero e homofobia que fica latente na declaração do parlamentar.

A opção pelo enunciado "dinheiro de auxílio-moradia eu usava para comer gente" e não outro, aparentemente, se deve ao fato de que essa pequena frase possui um caráter de fórmula (KRIEG-PLANQUE, 2016). Quando o jornalista, na condição de aforizador, opta por essa aforização atribuída a Bolsonaro, o leitor é interpelado a atribuir a esse enunciado um sentido que extrapola o seu sentido primeiro. Bolsonaro tem um histórico bastante ilustrativo de discursos machistas e preconceituosos, tendo inclusive sido condenado pelo Superior Tribunal de Justiça pelo crime de incitação ao estupro e injúria 
por um ataque à sua colega deputada Maria do Rosário em 2003. ${ }^{6}$ Ele recorreu ao Supremo Tribunal Federal e aguarda julgamento. À sua imagem já está atrelado o sentido de um homem machista, conservador, misógino e ortodoxo com seus princípios.

O enquadramento ao qual o jornal relacionou esse enunciado foi muito mais investido na produção de um exprimir uma convicção daquele personagem diante do mundo, o que se diz do enquadramento testemunhal (MAINGUENEAU, 2011). Isso porque a carga informativa do enunciado em questão é quase nula, e pode-se notar um superinvestimento subjetivo personalizante com a opção enunciativa.

Krieg-Planque (2016) avalia que a pequena frase é integrada à narração porque é construída como acontecimento, porque é associada a uma estratégia, a interesses. Os leitores de um título que relaciona um parlamentar a alguém que usa dinheiro de uma verba pública para "comer gente" são convidados a mobilizar uma série de estratégias interpretativas. Ou seja, são convidados a interpretar o destaque procurando (re)construir o percurso interpretativo desenhado pelo aforizador. Ao fim desse percurso, poderíamos supor que o jornal também pretende fazer esses leitores se questionarem sobre a condição de uma pessoa como essa ter legitimidade para assumir o cargo maior do executivo nacional, à frente da presidência da república.

A mesma linha de destacamento foi a opção do jornal Estado de Minas. O título "Bolsonaro diz que usou auxílio-moradia para 'comer gente" foi seguido da linha de apoio: "Em entrevista em Angra dos Reis, o pré-candidato à presidência afirmou ainda que vai vender o apartamento de Brasília e morar em uma mansão". Segue o excerto: "Ao ser confrontado, o pré-candidato negou ter usado verba do auxílio para financiar um de seus apartamentos e debochou: 'Como eu estava solteiro naquela época, esse dinheiro de auxílio-moradia eu usava para comer gente. Tá satisfeita agora ou não?', respondeu. Bolsonaro disse ainda que aquela era a resposta que a repórter merecia e perguntou se ela queria que ele prestasse 'continha'." (CIPRIANI, 2018).

O texto dá conta de fortalecer a imagem de deboche do deputado com relação às questões propostas pelos repórteres da Folha, inclusive quando apresenta a relação da sua resposta ser o que a repórter "merecia". Esse caráter é enfatizado quando é usado o substantivo 'confronto' como sinônimo de conversa ou entrevista. Outro elemento que auxilia o leitor no percurso interpretativo citado é o menosprezo com que o deputado trata a prestação de contas do dinheiro público que recebe do auxílio-moradia, citado pelo aforizador como "perguntou se ela queria que ele prestasse 'continha'."

\footnotetext{
6 "Não te estupro porque você não merece" foi a frase proferida por Bolsonaro à colega em 2003, em plenário, e repetida em dezembro de 2014. Em entrevista à Zero Hora, outro apontamento da opinião do parlamentar sobre as mulheres: "Mulher deve ganhar salário menor porque engravida. Quando ela voltar [da licença-maternidade], vai ter mais um mês de férias, ou seja, trabalhou cinco meses em um ano."
} 
Em comum nos dois textos (Gazeta do povo e Estado de Minas) está a opção por utilizar uma imagem do deputado para ilustrar as matérias. As opções de cada um dos jornais são bastante distintas, conforme a Figura 1:

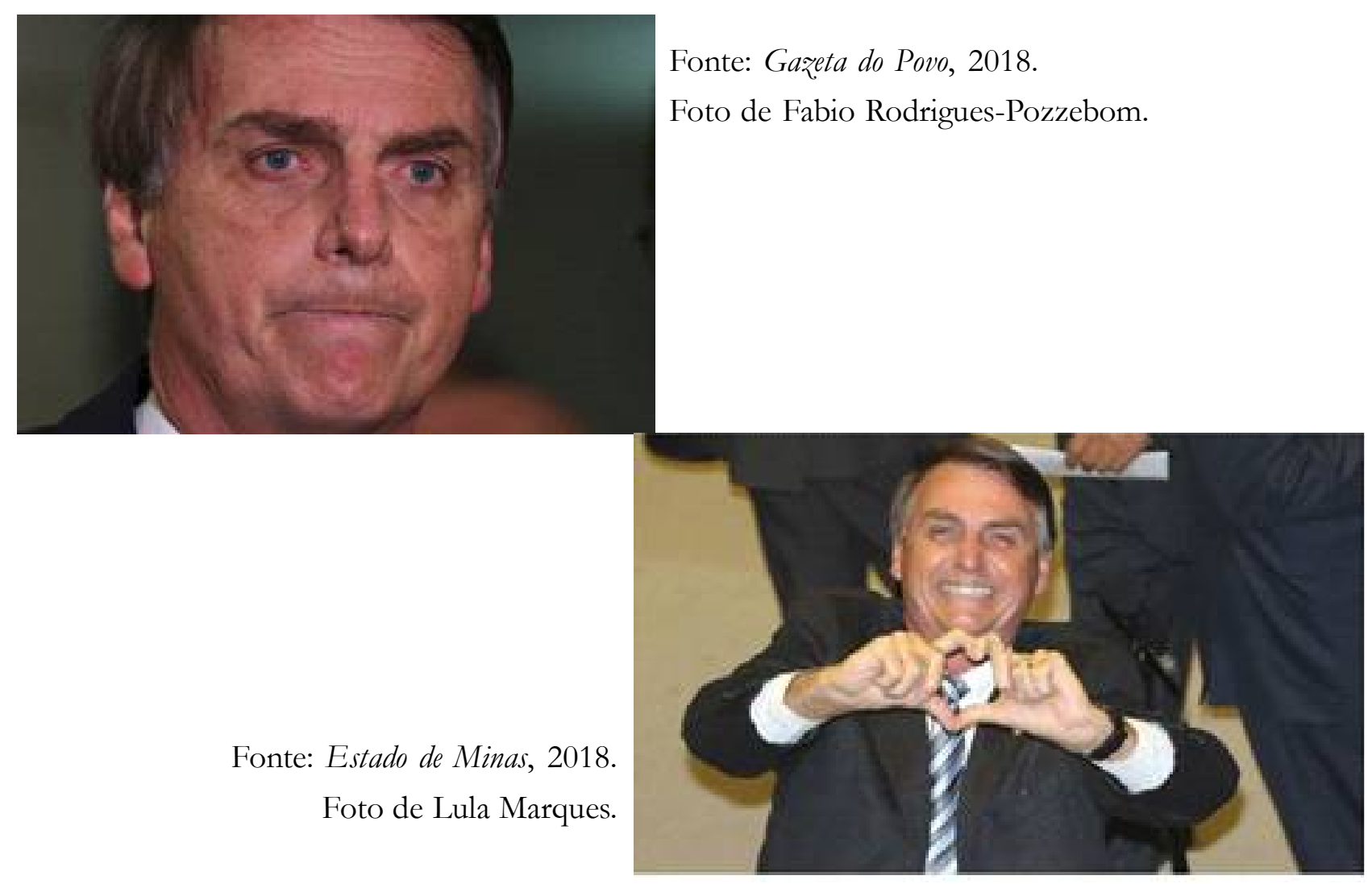

Figura 1 - Fotografias que ilustram os textos

Maingueneau (2014) considera que o aforizador de enunciados destacados na mídia geralmente opta por representar os locutores com uma foto de rosto, que funciona como uma assinatura e favorece seu reconhecimento como um subjectum, um termo que ele define como confluência entre o sujeito da enunciação e o sujeito jurídico/moral. Neste aspecto, o recorte eleito para análise também é expressivo na produção de sentido. Se a aforização tem por efeito personalizar os enunciados, autenticá-los de alguma forma, a fotografia funciona como um estímulo à formatação do sentido. As duas imagens são de arquivo, foram originalmente publicadas para dar conta de outros acontecimentos, porém minuciosamente eleitas para circularem novamente junto a essa nova enunciação, já que favorecem um efeito de veracidade do que é dito.

No caso da Gazeta do Povo, a expressão de Bolsonaro sustenta uma imagem de contrariedade. Um percurso interpretativo latente é de um Bolsonaro sendo forçado a reconhecer um delito, assumindo um erro diante do público, e bastante indignado com a situação. Talvez a intenção seja mostrar a dificuldade do parlamentar em lidar com opiniões contrárias às suas, ou mesmo responder quando é enfrentado por algum repórter, como 
foi o caso. Um outro sentido possível de ser evocado é de ausência de inteligência emocional, a falta de controle na gerência de suas emoções por parte do parlamentar, incapaz de permanecer estável quando precisa se esclarecer.

A fotografia eleita pelo Estado de Minas vai além. A imagem, que apresenta um Bolsonaro extremamente feliz, sorridente, sustenta um caminho interpretativo de deboche, de descrédito. É como se o aforizador, ao eleger a imagem para retratar a matéria, mostrasse o descaso do parlamentar com o bem público ao qual o texto se refere, um dinheiro gasto sem responsabilidade pelo parlamentar, que não se preocupa em assumir isso diante de repórteres. Outro sentido possível de ser referido na leitura dessa imagem é a de alguém acima do bem e do mal, inatingível para a justiça ou a opinião pública, alguém cujo discurso de moralidade oferece condições para atrair uma parcela da população que confia nele, acima de tudo, e o avaliza a colocar em prática seu "plano de governo moralizante".

A Revista Fórum fez questão de destacar que a sentença machista foi proferida por Bolsonaro a uma repórter, quando destaca, no início do título: "Bolsonaro para repórter da Folha: "Esse dinheiro de auxílio-moradia eu usava pra comer gente". A opção por destacar o gênero da repórter também aparece no texto interno da notícia, quando eles citam o adjetivo 'satisfeita'. O excerto é o seguinte: "O Deputado Federal, Jair Bolsonaro (PSC-RJ) perdeu a cabeça durante entrevista à Folha nesta quinta-feira (11). Ao responder sobre o uso indevido do auxílio-moradia, o presidenciável respondeu: "Como eu estava solteiro naquela época, esse dinheiro de auxílio-moradia eu usava pra comer gente, tá satisfeita agora ou não? Você tá satisfeita agora?” (REVISTA FÓRUM, 2018).

Um destacamento com este apontamento reforça ainda mais o preconceito de gênero explícito na fala, justamente pelo contexto social em que vivemos, em que o machismo ainda é tão presente, sendo considerado o preconceito mais praticado, de acordo com pesquisa Ibope de outubro de 2017..$^{7}$ O homem ainda assedia porque ele é socializado como alguém que, naturalmente, pode exercer domínio sobre a mulher. $\mathrm{E}$ a linha de apoio reforça a imagem de que Bolsonaro foi longe demais: "O presidenciável perdeu a cabeça ao falar sobre o uso indevido do auxílio-moradia". "Perdeu a cabeça", aqui, sugere um entendimento de que o parlamentar cometeu um erro na abordagem à repórter, passou dos limites da convivência numa relação profissional entre fonte e repórter, como é o caso, e nitidamente não possui a já citada inteligência emocional.

Essa opção reforça o entendimento de Baronas e Cox (2012), para os quais os destacamentos midiáticos vão além na circulação de enunciados, e revestem-se em potentes máquinas de produção de simulacros, de ideologias. Fica latente, na opção do

\footnotetext{
${ }^{7}$ Mais informações sobre os resultados da pesquisa podem ser acessados no site da revista Carta Capital, no texto "No Brasil o machismo é o preconceito mais praticado" (CARTA CAPITAL, 2018).
} 
Estado de Minas, por exemplo, quando apresenta o trecho em que Bolsonaro debocha da repórter e debocha da própria legislação que cobra que deputados prestem contas - "tá satisfeita agora? Quer que eu preste "continha?"' - que é feito um convite à uma mobilização de estratégias interpretativas que dão conta de apresentar o parlamentar como alguém sem crédito, sem condições de se tornar presidente. A foto só corrobora o sentido, considerando que pretende fazer crer que a fala - "dinheiro de auxílio-moradia eu usava pra comer gente" - por mais descabida que pareça, é realmente dele.

Aqui podemos fazer um aparte para tratar da questão dos aforizadores coletivos, proposta por Maingueneau (2011). Quando se diz que o repórter atua como aforizador, mas que este elege trechos da fala do entrevistado e os destaca, entre aspas, escolhendo ainda uma imagem para ser publicada conjuntamente, podemos compreender que estamos diante de dois aforizadores, sendo o próprio deputado também alçado a essa condição. A aforização institui uma cena de fala em que não há interação entre protagonista e auditório, diz Maingueneau. Aqui, estamos diante de repórteres que repercutem uma entrevista da qual não participaram. Eles elegem trechos da fala do protagonista e favorecem um entendimento de que ele está afirmando sua verdade, sem negociação, alçando-o à posição de aforizador também, quando sabemos que eles também são os responsáveis por essa manobra enunciativa de recorte e destacamento.

O Diário Catarinense seguiu opções bem semelhantes aos demais veículos listados nesta análise. A diferença é que o jornal destacou em seu título a frase anterior dita pelo parlamentar, apresentando seu estado civil à época: "Como estava solteiro, esse dinheiro de auxílio-moradia usava pra comer gente.”, diz Bolsonaro. Não há linha de apoio na notícia. O título foi destacado do seguinte excerto: "Na entrevista, Bolsonaro defendeu o recebimento de auxílio-moradia mesmo sendo proprietário de um imóvel em Brasília, negou irregularidades e também disparou críticas à imprensa. Como eu estava solteiro naquela época, esse dinheiro de auxílio-moradia eu usava pra comer gente. Tá satisfeita agora ou não? Você tá satisfeita agora? — disse, ao ser questionado se havia utilizado o benefício para comprar o próprio apartamento (DIÁRIO CATARINENSE, 2018).

Maingueneau (2008) afirma, em suas obras, que a aforização implica uma figura de enunciador que não apenas diz, mas mostra que diz aquilo que diz. Ou seja, o enunciado precisa apresentar a força de um enunciador que engloba uma posição. Podemos compreender, a partir da análise da entrevista de Bolsonaro à Folha e de outros quatro enunciados que a repercutiram em outros veículos de comunicação, que todos eles cumprem com esse propósito de apresentarem pistas do percurso interpretativo que pretendem que seus leitores mobilizem, pistas essas devidamente marcadas com aspas e, em dois dos casos citados, com uma imagem ilustrativa. Os aforizadores - neste caso, os repórteres que produziram e puseram a circular esses enunciados -, promoveram destaques de trechos da fala do deputado Jair Bolsonaro e, a partir de seus recortes, os leitores foram mobilizados a interpretar esses destaques. O movimento proposto também alçou 
Bolsonaro a aforizador, na medida em que as opções editoriais dos repórteres foram realizadas procurando que os leitores (re)construíssem os sentidos propostos por eles. Maingueneau aponta a problemática que emerge dessa responsabilização, já que, num primeiro momento, a sobreasseveração, de certa forma, desresponsabiliza o jornalista, e a responsabilidade dos enunciados recai sobre a figura do enunciador. Ocorre que, nos excertos analisados, aparentemente a intenção do político ao enunciar coincidiu com a intenção da imprensa em destacar, pois a fala dele se reveste de um caráter de descrédito para com a imprensa e, em última instância, com a sociedade, a qual tem acesso à fala dele por intermédio do veículo de comunicação.

Em uma sociedade em que as mídias audiovisuais dominam a produção de sentidos, a aforização principal exposta pelos veículos que circularam a entrevista - "esse dinheiro do auxílio-moradia eu usava para comer gente" - apresenta as características fundamentais destacadas por Maingueneau (2014): é generalizante, condensa uma mensagem da pessoa evocada; chama a atenção do público, mesmo que por meio de um texto emitido por um personagem controverso e de uma fala problemática. Ainda, é um enunciado enfático, que engaja uma tomada de posição forte, e que convém à espetacularização midiática.

O corpus analisado insta o leitor a realizar uma interpretação, e vai além, propondo um certo percurso interpretativo. É possível determinar que algumas subjetivações emerjam da leitura dos enunciados: por exemplo, votar ou não nesse candidato?

\section{Apontamentos em Forma de Conclusão}

Este trabalho procurou descrever e analisar o funcionamentos discursivo dos destacamentos midiáticos de uma entrevista do deputado Jair Bolsonaro à Folha de $S$. Paulo e os percursos interpretativos produzidos quando a entrevista circulou em outros veículos. À luz dos conceitos de destacabilidade, sobreasseveração e aforização, propostos por Maingueneau $(2008,2011,2014)$, buscou-se investigar o movimento de destextualização do contexto original da entrevista e os efeitos de representação que as manobras de sobreasseveração e aforização provocaram.

Foi possível constatar que os destaques efetuados pelos veículos de comunicação, ora na condição eles próprios de aforizadores, ora colocando Bolsonaro como sobreasseverador e, portanto, aforizador, não apenas convidam o leitor a realizar uma interpretação dos textos destacados, por meio das manobras enunciativas que impõem, como também apresentam um percurso interpretativo dos enunciados. Disperso nas entrelinhas, o discurso machista e preconceituoso se deixa flagrar por meio de um convite aos leitores para recuperarem informações já circuladas sobre o parlamentar, que dão conta de enquadrá-lo na condição de um homem cuja prática não condiz com o discurso de moralidade que prega. A forma de apresentação dos conteúdos faz um convite a uma mobilização de estratégias interpretativas que dão conta de apresentar o parlamentar como alguém sem crédito, sem condições de se tornar presidente. 
Compreendemos que a análise empreendida é um recorte pouco numeroso e, portanto, limitado em suas conclusões. Entretanto, acreditamos que ela fornece subsídios para, talvez, questionar as manobras enunciativas operadoras de sentidos. Há que se problematizar e tensionar o movimento de recorte operado pelos veículos de comunicação quando operam destacamentos e enunciações aforizantes, justamente no intuito de compreender a imprensa como uma máquina de produção de sentidos para além de publicação de fatos. Veículos de comunicação possuem interesses e colocam em prática estratégias discursivas que deem conta de fundamentar suas linhas editoriais; jornalistas, no geral, seguem as linhas editoriais dos veículos onde trabalham; a seleção dos acontecimentos a serem publicizados faz parte das estratégias dos veículos; a opção por alguns entrevistados é fundamental para a prática da estratégia discursiva; e, em última instância, a forma de apresentação desse texto e seus destaques, que é resultado final dessa lógica e parte iniciante de um processo de circulação de sentidos, é também intencional. Todos esses elementos carecem de um olhar e de discussões do ponto de vista discursivo, como propôs este trabalho.

\section{REFERÊNCIAS}

BARONAS, R. L.; COX, I. P. A circulação de enunciados destacados na mídia e a produção pletórica de enunciados. Signum: Estudos da Linguagem, Londrina, v. 15, n. 3 (esp.), p. 13-38, dez. 2012. Disponível em: http://bit.ly/2WYI36y. Acesso em: 27 jan. 2018.

BITTENCOURT. J. Bolsonaro para repórter da Folha: "Esse dinheiro de auxílio moradia eu usava pra comer gente”. Revista Fórum, 12 jan. 2018. Notícias. Disponível em: http://bit.ly/2ZmSsggRevFor. Acesso em: 01 fev. 2018.

CARTA CAPITAL. No Brasil, o machismo é o preconceito mais praticado. 13 out. 2017. Disponível em: http://bit.ly/31MZhYg. Acesso em: 01 fev. 2018.

CHARAUDEAU, P. Discurso politico. Tradução Fabiana Komesu e Dilson Ferreira da Cruz. 2. ed. 3. reimp. São Paulo: Contexto, 2017.

CIPRIANI, J. Bolsonaro diz que usou auxílio-moradia para 'comer gente'. Estado de Minas, 12 jan. 2018. Política. Disponível em: http://bit.ly/2Rd107FEsMi. Acesso em: 01 fev. 2018.

COLON, L. Com patrimônio multiplicado, Bolsonaro já declarou que sonegaria o “possível”. Folha de S. Paulo, 08 jan. 2018. Disponível em: http://bit.ly/2XuKZMp. Acesso em: 01 fev. 2018. 
DIÁRIO CATARINENSE. "Como estava solteiro, esse dinheiro de auxílio moradia usava pra comer gente.", diz Bolsonaro. 12 fev. 2018. Cotidiano. Disponível em: http://bit.ly/2FsvgpDDC. Acesso em: 01 fev. 2018.

FOSTER, G. Bolsonaro diz que não teme processos e faz nova ofensa: "Não merece ser estuprada porque é muito feia”. Zero Hora - GZH, 10 dez. 2014. Política.

Disponível em: http://bit.ly/3imI8MFZH. Acesso em: 01 fev. 2018.

GAZETA DO POVO. "Dinheiro de auxilio-moradia eu usava para comer gente", diz Bolsonaro. 12 jan. 2018. Política > República > Eleições 2018. Disponível em: http://bit.ly/2DM9H2WGazPo. Acesso em: 01 fev. 2018.

KRIEG-PLANQUE, A. A noção de fórmula em análise do discurso: quadro teórico e metodológico. Tradução Luciana Salazar e Sírio Possenti. São Paulo: Parábola, 2010.

KRIEG-PLANQUE, A. As pequenas frases: um objeto para análise dos discursos políticos e midiáticos. In: BARONAS, R. L.; LIMA, R. R.; MORAES, G. A.;

OLIVEIRA, H. (org.). Pequenas frases na politica brasileira, francesa e anglo-saxônica: abordagens discursivas. São Paulo: Pontes, 2016. p. 13-46.

MAINGUENEAU, D. Citação e destacabilidade. Tradução Roberto Leiser Baronas. In: MAINGUENEAU, D. Cenas da enunciação. São Paulo: Parábola, 2008. p. 75-92.

MAINGUENEAU, D. Aforização, enquadramento interpretativo e configuração humanista. In: MOMESSO, M. R.; SCHWARTZMANN, M. N.; ABRIATA, V. L. R.; FERREIRA, F. A. (org.). Discurso e linguagens: objetos de análise e perspectivas teóricas. Franca: UniFran, 2011. p. 15-34. (Coleção Mestrado em Linguística, v. 6).

MAINGUENEAU, D. Frases sem texto. Tradução Sírio Possenti. São Paulo: Parábola, 2014.

MATTOSO, C.; NOGUEIRA, I.; BRAGON, R. “Tem que pegar o meu patrimônio. Esquece meus filhos”, diz Bolsonaro. Folha de São Paulo, São Paulo, 11 jan. 2018. Editoria de Política. Disponível em: http://bit.ly/2J10a6L. Acesso em: 11 jan. 2018.

SOUZA, M. I. de. Dos discursos do Papa Francisco à produção e circulação de pequenas frases: a construção do papa heterodoxo. Linguagem em (Dis)Curso, Tubarão, v. 16, n. 3, p. 465-487, set./dez. 2016.

TRAQUINA, N. (org.). Jornalismo: questões, teorias e "estórias". 2. ed. Lisboa: Vega, 1999. 